much talk of the traditions of the English navy and the duty of England to be the first to reach the Pole. We fear the so-called traditions of the English navy must be made to conform to the requirements of modern science if she is to do any useful work in Polar discovery, just as they have been compelled to do in order that our navy may be able to keep abreast of the fighting power of other nations. To squander $30,000 \mathrm{l}$. in one huge attempt to reach the Pole would be as $\mathrm{mad}$ as for a merchant to embark all his capital in one hazardous undertaking. Polar research and Polar expeditions are not incompatible, but as Dr. Neumayer showed in an admirable address at the Danzig meeting of the German Association, the former must be subordinated to and guided by the results of the latter. Preparations are being made by nearly all the countries of Europe and by America for a regular Arctic siege, to begin in 1882 ; the days of Arctic campaigns are past. We have reached the precincts of the citadel itself, and now the sappers and miners must begin their slow but sure work, to be capped at the proper time by a grand assault. Germany, Austria, Norway, Sweden, Russia, Denmark, the United States, and we believe Canada are all to take part in this great work by establishing observing stations at suitable points all round the Polar area; while Italy is to send out next year a scientifically equipped expedition to the Antarctic region, our knowledge of which is meagre and uncertain. This last will really be an observing as well as an exploring expedition, preparatory to the establishment of an Antarctic station. Should our Geographical Society take any steps in the direction of Arctic work, we trust it will not be to encourage the foolish venture for which the country has been canvassed for subscriptions for years. We hope that Society will see that as a scientific body, its duty is to encourage a scientific method of work; and if it appeals to Government at all, let it be to urge it, for the honour of our country, to join in the concert of both hemispheres for the siege of the Polar citadel. We have already pointed out on several occasions the vast gains to science that might be expected from the work of a series of Polar observatories established on the plans so ably sketched by Lieut. Weyprecht. As Dr. Neumayer said in the address alluded to, men of science do not demand practical or so-called utilitarian reasons before giving their adhesion to any new work; it is enough if it can be shown that such work will conduce to the advancement of knowledge. And that Weyprecht's scheme of Polar observatories, of which so many Governments approve, will lead to vast additions being made to scientific knowledge, no man of science needs to be told. In meteorology, terrestrial magnetism, biology, geology, and glacial physics, the gains would be immense; and the history of science has taught us over and over again that the surest path to practical and beneficent results is through the gate of pure scientific research. Every day is the science of meteorology becoming more and more important ; but until we are thoroughly acquainted with the meteorology of the Arctic regions, that most practical of sciences is deprived of what is perhaps its most important factor. But one element of the international scheme is that of Polar exploration, conducted, however, on scientific method, and along lines indi ated by a scientific knowledge of Arctic conditions such as can only be obtained by permanent observing stations. What success is likely to result from Arctic work carried out on such a method was triumphantly shown by Baron Nordenskjöld when he. sailed along the North-East Passage in the Vega. Why then should not England set up a station on Franz-Josef Land, and another say on some part of the American coast? Let the station be provided with the means of carrying out exploration in whatever direction and by whatever means the results of continued observation may indicate -as far as the Pole itself, if nee 1 be. Unless we are blind to the teachings of science and the lessons of our last expensive expedition, it is clear that this is the only sure method of reaching the Pole, if it be thought absolutely necessary for the credit of England that she should be the first to get at a point which it will take considerable trouble to spot. If our Government be well advised, we are sure they will never give the public funds either for any great national expedition modelled on the lines of the past, nor to any private chimera got up for the glory of one man and the gratification of balloonists. We do not see how, without national discredit, England can keep aloof from an international scheme, the scientific and practical results of which will be of world-wide importance; and it is the duty of the Geographical Socicty to lend all the weight of its influence to induce the Englis' Government to take up its share in the new and only effectual method of Polar exploration.

\section{THE SANITARY ASSURANCE ASSOCIATION}

$\mathrm{T} \mathrm{T}$ is admitted on all hands that a vast amount of unnecessary disease, suffering, and death is caused by defective sanitary arrangements, especially as regards drainage. A few years ago, so long as there was no foul smell, and all the pipes were "properly trapped," everybody was satisfied; but properly trapped usually meant improperly ventilated, or not ventilated at all, and we know now that foul gases will pass steadily, continuously, and certainly through water in traps.

Clinical observation having demonstrated the fact that sewer air produced diseases, the prevention of the entering of such foul air into houses became of paramount importance; and the matter being thus brought to so narrow an issue, the application of well-known physical laws was all that was required; it was necessary to study the circumstances under which foul air was produced, to prevent its production as far as possible, and to take such precautions that foul air, even if formed, could not accumulate and could not find its way into houses.

Science has done much, both directly and indirectly, towards the prolongation of life; and certainly not the least important of the results of the application of scientific methods to this end in recent years has been the discovery of the ways in which a house can be made practically sewer-air proof. The laws of health are being studied more and more every day, and will soon be taught as a matter of course in all our schools; they are already recognised as a special subject of study at the Universities. People are beginning to perceive that their health is a matter which is very largely indeed in their own hands, and are beginning to turn this knowledge to account in the matter of house sanitation. At the first 
meeting of the Sanitary Assurance Association, presided over by Sir Joseph Fayrer, eminent members of the two professions which must always occupy the most reponsible position in connection with household sanitary matters, the professions of medicine and architecture, bore ample evidence to this fact, and at the same time to the necessity for some organisation by which the benefit of the best advice on such matters may be brought within the reach of the many. At this meeting Mr. Mark $H$. Judge pointed out that the Association "was the outcome of efforts which had been going on for some months to bring together architects and medical men in connection with the important question of house sanitation," and the names already identified with the Association are a sufficient guarantee that it will be both practical and permanent in its character. Sir Joseph Fayrer rightly stated in his opening address that "there is a terrible absence of all supervision of sanitary arrangements and drainage in many of the houses of the metropolis," and that although the richer classes of the population are able to get that sanitary advice which will enable them to make their houses wholesome, "there is an enormous population left, as regards which such a thing is hardly possible." Saying that he believed the idea was beginning to grow that "sanitation generally will increase the value of life," he continued, "over and over again it has come to my knowledge, and even occurred under my own observation, that families, children and servants, have suffered by the defects of drainage or sewer air-that great enemy to public health. I would venture to offer no opinion as to the nature of the diseases that proceed from sewer air, nor even enter into any discussion on the precise character of the air-the nature of the germs and the character of the poisons that it communicates; but that it does destroy health and induce disease is beyond a doubt. That it is greatly under the control of sanitary law is equally certain, and there are men now who have so studied and comprehended the nature of those laws, that they are able, practically as well as theoretically, to give that assistance and that advice which should render those conditions almost innocuous-in fact it should prevent them altogether."

Dr. Andrew Clark, after stating that he considered the Association "one of the most pressing needs of the present time," added:- "Furthermore I am convinced that if the Association can secure and retain the services of men with the scientific and practical knowledge possessed by Prof. Corfield, and will hold itself free from undertaking the execution of the works which it may suggest, superintend, and from time to time certify as sufficient, it will do important service to the public, and confer much and just credit upon all concerned."

Mr. Edwin Chadwick, the veteran sanitarian, said that "he constantly advised people, from his knowledge, 'Do not take that house unless you have it examined first. If the drains are out of order do not take it till they are put right. That was exactly what this Association had to supply."

We are happy to state that the formation of the Association was decided upon, and the following gentlemen were appointed a committee to organise it:- George Aitchison, F.R.I.B.A. ; Prof. W. H. Corfield, M.A.,
M.D.; Prof. F. de Chaumont, M.D., F.R.S. ; Mark H. Judge, Prof. T. Hayter Lewis, F.S.A. ; H. Rutherford, Barrister-at-Law; with Prof. Corfield as Chief Sanitary Officer, and Mr. Judge as Surveyor.

It is surely as necessary to be assured against preventible diseases as it is to be assured against fire, and we see from the preliminary prospectus issued that it is intended to give persons who place their houses on the Assurance Register certificates that their houses are in a satisfactory sanitary condition, and to endorse such certificates from time to time ; this latter point is of great importance, as it is only by regular inspection at stated intervals that it is possible to ascertain that all continues to work satisfactorily.

A very important feature is also the proposal to examine and report on the plans of new houses, for there is at present absolutely no control exerted over the sanitary arrangements of new houses in the metropolis.

We have given such prominence to this matter because we believe that the Association will supply a widely-felt want, and will do good not only directly but indirectly too; thus wise builders will take care to have their houses supervised and certified, and will reap their reward in increased facilities for letting ; architects will submit their plans for criticism and suggestion; and so the public will in many ways reap a lasting benefit. In this country few new things succeed unless public opinion is ripe for them. We are slow to adopt new ideas; but we have now learnt the importance of preventing disease, we believe that much of our health depends on the perfection of the drainage arrangements of our houses, and we are ready to place them in the hands of an association in which we can have confidence.

\section{HINCKS'S "BRITISH MARINE POLYZOA"}

A History of the British Marine Polyzoa. By Thomas Hincks, B.A., F.R.S. (London : J. Van Voorst, r88o.)

THE value to science of Mr. Van Voorst's splendid 1 series of volumes descriptive of the Natural History of the British Islands is scarcely to be overrated. The monographs are all the work of most eminent naturalists, in whor perfect confidence may be placed, and they are sumptuously printed and illustrated with abundance of excellent plates and woodcuts. The thanks of naturalists generally are certainly c'ue to Mr. Van Voorst. The present work is fully equal in merit to its predecessors; it consists of two volumes--one of 600 pages of text, the other containing eighty-three lithographic plates. Mr. Hincks, whose industry is inclefatigable, has already contributed to Mr. Van Voorst's series the well-known excclIent monograph on the Hydroid Zoophytes. The labour involved in the production of a monograph such as that now under consideration is very great. All the 235 species occurring on the British coast are figured, with one or two exceptions in cases where specimens do not exist for the purpose. All the figures have been drawn by the author himself and beautifully lithographed by Mr. Hollick. Further figures are added taken from various monographs where such are necessary for the elucidation of the subject.

The work commences with an introduction, in which the author, after expressing his obligation to Mr. Busk, 